\title{
La guerra civil peruana de 1854. Los entresijos de una revolución/
}

\author{
The Peruvian Civil War of 1854.
}

The Framework of a Revolution

Víctor Peralta Ruiz

Centro de Ciencias Humanas y Sociales, CSIC, Madrid

El artículo se propone analizar la complejidad de la guerra civil que estalló en el Perú en 1854 entre el gobierno constitucional del general José Rufino Echenique y los revolucionarios liderados por el general Ramón Castilla. Se estudiarán los distintos pronunciamientos antigubernamentales, el papel jugado por los ejércitos y las guardias nacionales en uno y otro bando y, por último, la política de premiaciones políticas con todos sus aliados, especialmente los liberales, que dispuso el bando vencedor de Castilla una vez establecido en el poder.

Palabras Clave: Guerra Civil; Violencia política; Perú; Siglo XIX; Ramón Castilla.

The paper attempts to analyze the complexity of the civil war that broke out in Peru in 1854 between the constitutional government of General Jose Rufino Echenique and revolutionaries led by General Ramón Castilla. I will study the various antigovernment statements, the role played by the army and the National Guard on either side. Finally I will develop the policy of political awards with all its allies, especially the liberals, decided by Castilla's winning side once established in the power.

Keywords: Civil War; Political Violence; Peru; XIX Century; Ramon Castilla. 


\section{La Guerra Civil peruana de 1854. Los entresijos de una revolución ${ }^{1}$}

Los más recientes estudios sobre los estados latinoamericanos del siglo XIX no solo consideran a la violencia política parte racional del juego político, sino que han replanteado la mirada a las revoluciones, guerras civiles y golpes de Estado desde las propias lógicas discursivas y prácticas políticas de su época. Se llega así a una propuesta que considera a la violencia como «un ingrediente de la realidad social que sólo se convierte en un hecho discernible y empíricamente observable en un contexto sociohistórico determinado». ${ }^{2} \mathrm{Al}$ igual que en otras realidades latinoamericanas, la historiografía peruana ofrece un creciente interés por reevaluar los hechos de violencia en la política decimonónica tanto por motivaciones académicas como por razones ligadas al clima bélico vivido en la década de 1980. Sensibilizada por esta última circunstancia, Cecilia Méndez sostiene que el Perú carece de una memoria nacional de sus guerras civiles decimonónicas y que eso ha llevado al desconocimiento del papel que tuvieron en ese escenario las poblaciones rurales que participaron no sólo con las armas sino también ejerciendo «tareas de gobierno y control social que fueron claves en el proceso de formación del Estado nacional». ${ }^{3}$ Cristóbal Aljovín estudia las revoluciones de la primera mitad del siglo XIX con la intención de demostrar que la ruptura del orden constitucional fue un componente esencial de la cultura política, por lo que el «republicanismo peruano estaba en una constante pugna entre una lógica representativa y una lógica jacobina». ${ }^{4}$ Ello es matizado por Gabriela Chiaramonti que alerta de que la herencia constitucional gaditana favorecía que la titularidad y ejercicio de la soberanía no se percibiesen separados, sintiéndose los pueblos titulares originarios y por lo tanto autorizados en todo momento a reapropiársela mediante pronunciamientos.

Como complemento de las propuestas anteriores, este trabajo sobre la guerra civil de 1854 abordará la imbricación de las narrativas y las prácticas de movilización implícitas en los pronunciamientos revolucionarios con las políticas de negociación desplegadas por los contendientes de cara

1 Este trabajo pertenece al proyecto I+D HAR2010-17580.

2 Consúltese el debate sobre el tema desarrollado en las presentaciones del dossier Irurozqui, 2009, 11-18 y del dossier Irurozqui, 2012, 415-422.

3 Méndez y Granados, 2011, 94.

4 Aljovín de Losada, 1993-1995, 257.

5 Chiaramonti, 2007, 150-179. 
a la consolidación gubernamental. El conflicto comenzó con un estallido revolucionario en la ciudad de Ica el 21 de diciembre de 1853 y culminó con la batalla de La Palma en Lima el 5 de enero de 1855. Los historiadores la han considerado como una revolución liberal porque en el bando vencedor participaron conspicuos ideólogos liberales como Manuel Toribio Ureta, los hermanos Pedro y José Gálvez y Domingo Elías. También se la asume liberal porque Castilla dispuso la abolición del tributo el 5 de julio de 1854 y la supresión de la esclavitud el 5 de diciembre de 1854. Más allá de lo pertinente o no de esa clasificación ideológica, mi intención es dilucidar la trama de cooptaciones, negociaciones, intercambios sociopolíticos nacionales e internacionales de esa revolución. Por un lado, ello implica cuestionar el automatismo nominativo que induce a reducir el liberalismo a un individualismo posesivo y que, en consecuencia, impide comprender el desarrollo contextual y la comprensión social de esta noción por convertir en pecado contra la modernidad cualquier atisbo corporativo o clientelar. Por otro lado, ello supone atender a la organización espacial y social del Perú, a las rivalidades territoriales consecuentes en torno al modelo de Estado y a las redefiniciones grupales a partir de la oportunidad generada por la competencia política. Para indagar en lo complejo y multifacético del desarrollo revolucionario se hará hincapié en que el llamado ejército libertador liderado por el general Ramón Castilla apeló con éxito al principio liberal en la medida en que ello fue también acompañado de cooptaciones formales e informales de múltiples fuerzas e instituciones sociales y regionales que poco o nada tenían que ver con lo ideológico. Su triunfo sobre el bando constitucional del presidente José Rufino Echenique se gestó no sólo en el campo de batalla sino en los escenarios donde Castilla negoció la coparticipación gubernamental y la concesión de estatus, bienes y prebendas a los cuerpos y sectores sociales que lo apoyaran. Pero para hacerlo contó tanto con una infraestructura institucional de legitimación como con una cultura de la movilización centradas en el ciudadano armado.

Para demostrar lo dicho anteriormente, se analizarán las interrelaciones de los pronunciamientos contra Echenique realizados por distintos actores. También se atenderá a la presencia del ejército en la vida política y al peso de las guardias nacionales como forma de participación predilecta y obligatoria de la sociedad civil en el conflicto. A diferencia del caso argentino, donde la fortaleza institucional y regional de este cuerpo de milicias, más que el propio ejército, fue clave en el resultado final de las gue- 
rras civiles, ${ }^{6}$ en el caso peruano la revolución de 1854 mostrará cómo, pese al interés del líder revolucionario civil Domingo Elías de convertirlas en decisivas fuerzas disuasorias de abusos constitucionales, la estructura del Estado peruano no favoreció su firme institucionalización como alternativa armada al ejército, produciéndose una erosión del principio de pueblo en armas por esa vía. Por último, se incursionará en la política de reparto de recompensas políticas por parte del bando vencedor como modalidad para salvaguardar la viabilidad del régimen establecido, haciendo incidencia en que los límites de la negociación entre partidos se relacionaron con la diferente concepción acerca del peso de los poderes ejecutivo y legislativo.

\section{El papel de los pronunciamientos en el escenario bélico}

La revolución de 1854, que lideró triunfalmente el general Ramón Castilla, apoyado por Elías, en contra del gobierno del general José Rufino Echenique, suscita hasta la actualidad diversas y encontradas interpretaciones. Como ejemplo de esa discrepancia basta contrastar lo afirmado por los historiadores Jorge Basadre y Rubén Vargas Ugarte. Mientras el primero define a la revolución como un «violento plebiscito» en el que la ira popular pudo manifestarse en contra de la corrupción gubernamental, el segundo la enjuicia como el producto de la ambición de poder de Elías y Castilla ya que «la revolución no se justificaba en manera alguna, los males si acaso eran ciertos, podían remediarse constitucionalmente». ${ }^{7}$ Enfoques más recientes tienden a valorar el suceso adoptando el punto de vista del vencedor. De acuerdo con esta versión el uso de la violencia se justifica como una reacción a la venalidad y corrupción derivadas del proceso de consolidación de la deuda interna, un camino hacia el enriquecimiento personal acelerado gracias a los ingresos provenientes de la exportación del guano de las islas. Se afirma, así, que como la consolidación «fue un fenómeno que benefició básicamente a la clase dominante capitalina, los notables y pueblos provincianos utilizaron el escándalo de la consolidación como un motivo más para rechazar al gobierno de Echenique y la corrupción capitalina». ${ }^{8}$ Como complemento de la afirmación anterior se ha añadido que, dossier

6 Sábato, 2002, 149-169; Macías, 2003, 137-151. Véanse también los textos incluidos en este

7 Basadre, 1964, III, 1066; Vargas Ugarte, 1971, 57.

8 Quiroz, 1987, 131. 
además de la lucha contra la corrupción, los revolucionarios optaron por esa vía armada ante «la imposibilidad de lograr cambios por un camino legal debido a la sujeción de los congresos de 1851 y $1853 » .{ }^{9}$ Finalmente, en una perspectiva más ajustada a lo que sería la política clientelar de la época se sostiene que la guerra civil fue un ajuste de cuentas a los echeniquistas por parte de las facciones políticas derrotadas (vivanquistas, eliístas y liberales) en las elección presidencial de $1851 .^{10}$

Los inicios de la revolución cronológicamente deben remontarse a las dos cartas que Domingo Elías dirigió al presidente Echenique, en las que se refirió al mismo como «respetado general y amigo», y que fueron publicadas en el diario El Comercio el 12 y 16 de agosto de 1853. En ellas denunciaba la consolidación como un fraude por haber generado numerosos expedientes falsificados que habían permitido el enriquecimiento de personajes allegados al gobierno. La carta provocó que el presidente, autorizado por el congreso, dispusiese el encarcelamiento de Elías, quien tras prometer que se alejaría del país, fue liberado en septiembre. Elías se asiló en la legación francesa y partió hacia Guayaquil, pero apenas desembarcó en esta ciudad se impuso como propósito organizar una expedición revolucionaria contra el gobierno peruano. Sin emitir ninguna proclama, Elías ocupó con sus escasas fuerzas la localidad de Tumbes, siendo la asonada fácilmente desarticulada por la gendarmería el 21 de octubre de 1853.

Tras el fracaso de su complot, Elías se ocultó y fugó con dirección a Lima en donde entró clandestinamente en contacto con el general Ramón Castilla, quien ejerció la presidencia entre 1845 y 1851, con el propósito de lograr su apoyo para la revolución que estaba empeñado en liderar. Obtenido el compromiso parcial del ex presidente, Elías eligió Ica, su tierra natal, como el escenario de su rebelión por contar allí con una amplia red de apoyos políticos de naturaleza clientelar y familiar formalizados en torno al Club Progresista, organización que había secundado su candidatura presidencial en 1851. Para tener éxito le era vital contar con la aquiescencia del ejército y en eso se basó su oferta a Castilla para que este asumiese la jefatura militar del movimiento, mientras él se arrogaba la jefatura política. ${ }^{11}$

9 Sobrevilla Perea, 2004, 231.

10 Mc Evoy, 1963, 211-241.

11 También confiaba Elías en que en Lima su pronunciamiento sería secundado por las tropas comandadas por el general Alejandro Deustua, al sentirse este frustrado por haber otorgado Echenique al general Juan Crisostomo Torrico y no a él su apoyo para ser el futuro candidato del gobierno a la presidencia. Pero Deustua finalmente se reconcilió con Echenique. 
Elías inició la revolución en Ica el 21 de diciembre de 1853. El pronunciamiento hecho público ese mismo día estableció una junta gubernativa de provincia declarada «en situación independiente» de Lima hasta que se reuniese un congreso general. Reconocía que Ica lideraba la reacción contra la tiranía echeniquista por la lesiva corrupción derivada de la consolidación de la deuda interna a través de la que «unos pocos hombres marcados con el oprobioso sello de la reprobación, han exprimido de vuestras arcas la cuantiosa suma de treinta y cinco millones de pesos, mientras que nuestros campos se esterilizan por la falta de brazos y de irrigación, nuestro comercio se halla sin vida y la industria nacional en sus últimas palpitaciones». ${ }^{12}$ A esa razón se añadía una segunda causa para derrocar a Echenique referida al hecho de que el gobierno no hubiese aún reivindicado por las armas los derechos nacionales ultrajados por Bolivia, estableciéndose que el papel de limpiar el honor patrio debía corresponderle «al esclarecido guerrero gran mariscal D. Ramón Castilla». Resulta necesario recordar que el conflicto con el vecino del sur había estallado en 1853 como resultado del incumplimiento por parte de Bolivia del tratado comercial firmado en 1847. Echenique había exigido al gobierno de Manuel Isidoro Belzu que admitiese a un representante diplomático en Potosí que verificara el fin de la emisión de la moneda feble que había provocado que las provincias del sur peruano se vieran inundadas por ese circulante. Pero Belzu reaccionó con indignación ante ese intento de protectorado económico de su vecino andino y ordenó la expulsión del cónsul peruano. El casus belli fue planteado en Lima en el congreso, que autorizó a Echenique a declarar la guerra en mayo de 1853. La ofensiva peruana comenzó con una incursión naval que se limitó a ocupar el puerto de Cobija, siendo pospuesta sin embargo en varias ocasiones la anunciada invasión militar que se preparaba en Puno. Esta inoperatividad del ejército proporcionaría a los revolucionarios un filón argumentativo para denunciar la dejadez del gobierno de Echenique en la resolución de la crisis con Bolivia por la vía armada.

Las tropas del ejército comandado por el ministro de Guerra, el general Torrico, desembarcaron en Pisco y derrotaron el 7 de enero de 1854 a los milicianos elíístas en las inmediaciones del cerro de Saraja. El saldo del combate con el que se inició la guerra civil de 1854 fue de ciento cuarenta milicianos iqueños muertos. Elías logró huir a Chile y desapareció temporalmente del escenario, mientras que Castilla, tras rechazar el gobierno su

12 Registro Oficial, Lima, 24 de diciembre de 1853. 
ofrecimiento de mediador, se asiló en un navío de guerra francés apostado en El Callao. Paradójicamente, el mismo día en que se produjeron los sucesos de Saraja, tuvo lugar un segundo estallido revolucionario en Arequipa liderado por «los señores Diego Masías y sus tres hermanos, Fernando Alvizuri, Domingo Gamio y algunos artesanos» ${ }^{13}$ que culminó con la huida de la ciudad del prefecto Rivero y de la gendarmería. Jorge Basadre afirma que la mayoría de los líderes de la revuelta eran partidarios del general Vivanco, quien estaba exiliado en Chile como resultado del fracaso de su intentona revolucionaria de 1851, y actuaban motivados por lo que ocurría en Ica sin conocer aún su desenlace adverso.

El acta justificatoria de la junta departamental rebelde, que en su fase inicial la comandaba el prefecto Alvizuri, señaló tres causas para explicar el levantamiento: primera, la mayor parte de los pueblos del norte habían desconocido a la autoridad que mandaba en Lima; segunda, el gobierno echeniquista había cometido una «punible indolencia» al desatender el clamor popular de vengar los ultrajes inferidos por Bolivia; y, tercera, «el referido gobierno de la capital ha hostilizado a este departamento por todos los medios que ha tenido a su alcance». ${ }^{14}$ Como puede apreciarse el pronunciamiento arequipeño no utilizó el justificante de la corrupción derivada del proceso de consolidación de la deuda y sólo coincidió con la provincia vecina de Ica en reclamar que se hiciera la guerra al régimen de Belzu. Por lo demás se exageraba la situación de anomalía en que se hallaban las provincias del norte ${ }^{15} \mathrm{y}$, a la vez, se transmitía una sensación de humillación asociada con el régimen de Echenique y se la personificaba en la figura del general Trinidad Morán, prócer de la independencia de origen venezolano, quien tuvo una polémica actuación como comandante de la guarnición arequipeña y se ganó la animadversión de parte del pueblo.

Paralelamente y sin estar sincronizado con el levantamiento de Arequipa, se produjo el pronunciamiento del general Fermín del Castillo en el departamento de Junín el 7 de febrero de 1854. Este personaje asumió la condición de jefe superior del departamento y justificó su proceder del siguiente modo: «cuando todos los pueblos del Perú se convencieron de la

13 Valdivia, 1956, 207.

14 Basadre, 1964, III, 1071

15 El acta alude a la rebelión de las provincias de Chiclayo el 1 de enero de 1854 y de Cajamarca ocurrida cuatro días más tarde. Mientras la de Chiclayo puede vincularse al movimiento eliísta, la movilización de Cajamarca fue más bien una reivindicación regionalista ya que su objetivo fue alcanzar la condición de departamento y, por tanto, segregarse de La Libertad. 
necesidad de una revolución; cuando los verdaderos patriotas vieron humillado y escarnecido el honor nacional, cuando por el órgano del Gobierno se hacía difícil la reparación de los ultrajes recibidos por el Gabinete de Bolivia; cuando un mal sistema administrativo empezó por conculcar el verdadero pacto social, la idea revolucionaria cundió». ${ }^{16}$ Por administración defectuosa, Castillo comprendía a la corrupción gubernamental asociada con la consolidación denunciada por Elías en sus cartas a Echenique. En consecuencia, el pronunciamiento de Junín al ser similar al formulado unas semanas antes en Ica puede considerarse como un sucedáneo del mismo. Castillo era muy claro en enfatizar que «en esas circunstancias no se reconocía otro caudillo que el pueblo mismo; y la persona de D. Ramón Castilla fluctuaba entonces en la más completa indecisión». ${ }^{17} \mathrm{El}$ movimiento fue desarticulado el 13 de febrero por dos divisiones del gobierno al mando de los generales Deustua y Salaverry. Castillo huyó hacia el centro del país en donde terminó sumándose a las fuerzas de Castilla.

Retomando el caso de la revolución de Arequipa, durante las primeras semanas del levantamiento ocurrió la circunstancia anormal de que los juntistas no sabían a qué líder secundar. El deán Juan Gualberto Valdivia, testigo de la época, relata que la noticia de que el general Juan Antonio Pezet, junto con la división militar de Puno, se aproximaba a la ciudad con el propósito de someterla dividió a los revolucionarios. Mientras unos apoyaban la oferta de mediación del coronel Buendía, a quien Pezet había enviado para garantizarles la ausencia de represalias si se retornaba al orden constitucional, otros la rechazaban. En esta tesitura se manifestó oportunamente el protagonismo del general Castilla. A mediados de febrero este militar decidió implicarse en el conflicto arequipeño. Transbordó del navío francés a un vapor de comercio que lo ayudó a desembarcar en una caleta próxima al pueblo de Atico desde donde se dirigió a Camaná. Su entrada en la capital arequipeña se produjo el 13 de febrero y desde ese día fue ungido como jefe de la revolución. ¿Cómo fue que Castilla logró obtener el apoyo de una población mayoritariamente conservadora y partidaria del general Vivanco, su encarnizado enemigo político, y que por esa identidad había definido su revolución como la de una regeneración reñida con el liberalismo? La respuesta la proporcionó el propio Vivanco en un folleto que redactó y publicó en pleno desarrollo del conflicto. Según este mili-

16 Castillo, 1855, 13.

17 Ibidem, 14. 
tar, Castilla había anunciado a los arequipeños que asumía el liderazgo de esa revolución de común acuerdo con él, prometiéndoles que pronto se sumaría a la causa revolucionaria. Vivanco denunció que ello era falso porque ninguna comunicación previa se había producido entre ambos y, más bien, «durante este tiempo su principal ocupación [de Castilla] fue consumar y ratificar el engaño de Arequipa... y siempre agregaba [por calles y plazas] que yo debía ser el presidente». ${ }^{18}$ Fue así comprensible que ante el anuncio de que el ejército de Pezet estaba próximo a atacar la ciudad, el prefecto reconociera a Castilla como jefe del ejército regenerador. Seguidamente, le fue conferido el título de jefe político del departamento y junto con sus agentes, entre los que destacó el deán Valdivia, se dedicó a organizar las milicias y barricadas.

El anunciado asalto de Arequipa por parte del ejército constitucional no se llegó a producir porque Torrico, al recibir noticias de nuevos pronunciamientos antigubernamentales en Puno y Moquegua que en su opinión variaban su situación de sitiador a sitiado, decidió retirarse de Paucarpata. Las furibundas críticas vertidas en Lima contra él por el fiasco de Arequipa obligaron a Echenique a quitarle su confianza y, en compensación, encomendarle una misión a Francia que le alejó definitivamente del país. Fortalecido por esa circunstancia, Castilla decidió aprovecharla para extender la revolución al conjunto de los departamentos del sur. Mientras él se dirigía con parte de las tropas hacia el Cuzco, sus agentes arequipeños redactaron una nueva acta para reformular los principios esgrimidos el 7 de enero. El nuevo pronunciamiento constaba de cuatro artículos. El primero confería a Castilla el supremo mando de la República con el título de Libertador de la «tiranía gubernamental» de Echenique; el segundo le daba plenos poderes políticos a condición de que convocase una asamblea constituyente en el plazo máximo de un mes contados desde la pacificación del país; el tercero creaba en Arequipa una junta o consejo departamental de seis miembros subsistente sólo hasta la reunión de la asamblea nacional y cuya única función sería informar sobre las reformas que conviniese adoptar por el gobierno en beneficio de la región; y el cuarto facultaba al prefecto para proponer a los individuos que considerase como los más idóneos para integrar el consejo. ${ }^{19}$

18 Vivanco, 1854, 29.

19 El acta es reproducida por Vivanco (1854); en cambio Valdivia (1956) la omite a pesar de ser protagonista de su redacción. 
La transformación de los heterogéneos objetivos de las regiones revolucionadas que se consiguió con la nueva acta constituida a partir de la proclama del 1 de mayo de 1854 y en la que Castilla aceptaba su nombramiento como presidente provisorio de la República con facultades extraordinarias fue espectacular. Solo se mantuvo de los pronunciamientos anteriores el común objetivo de la destitución de Echenique. El resto de las demandas, como la guerra con Bolivia o la revisión de los negociados de la consolidación, etc., quedaban supeditados a su inclusión en las demandas de los consejos departamentales. Así el artículo tercero de la referida acta expresaba que la incumbencia exclusiva de estos consejos sería «la de indicar las reformas locales y generales que creyeren convenientes, presentando las primeras a la aprobación del gobierno y las segundas a las cámaras reunidas en congreso o convención nacional». ${ }^{20}$ Castilla cerraba, así, el ciclo de los pronunciamientos de la etapa inicial de la guerra civil con un reparto negociado de futuros beneficios a los departamentos que apoyaran su causa.

La desactivación en el pronunciamiento de mayo de la demanda belicista contra Bolivia le garantizaba la viabilidad para iniciar negociaciones con el gobierno del general Belzu para adquirir las armas y los pertrechos que requería su ejército libertador. De paso, lograba convencer a los departamentos del sur de que era necesario abolir la constitución de 1839, por la que paradójicamente había luchado en 1845, por ser el principal impedimento para su reelección presidencial. A cambio, su actuación política quedaba sometida a lo que los consejos departamentales dispusieran, otorgándoles facultades ejecutivas que no habían tenido hasta ese momento. Para reforzar su alianza con las provincias del sur, Castilla aceptó demandas locales como la supresión del derecho municipal de molinos que afectaba a los comerciantes arequipeños o la creación de una provincia en el Cercado de Puno y de otra en el valle de Majes a la que se bautizó con su apellido. ${ }^{21}$

\section{La guerra civil y la cooptación del ejército y de las guardias nacionales}

El gobierno de Echenique se inició el 20 de abril de 1851 con la transmisión del mando supremo por parte del presidente saliente Castilla. Fue la

20 Republica Peruana, 1857, I, 266.

21 Instituto Libertador Ramón Castilla, 1855, I, 266. 
primera vez que en la República tuvo lugar un ceremonial político de este tipo, ya que solo había logrado concluir su mandato el general Agustín Gamarra en 1833. Pero este no había entregado la presidencia a su sucesor, el general Luis José de Orbegoso, sino que le nombró presidente una convención nacional sin que mediase un comicio popular. Echenique había resultado vencedor en una contienda electoral, marcada por la violencia, la manipulación y el favoritismo presidencial, en la que había competido con el general Vivanco y Domingo Elías. ${ }^{22}$ Echenique estrenó una forma de gobernar que difería de la practicada por su antecesor en el cargo. En lo relativo a su política interna, si Castilla había concedido parcelas de poder y prebendas económicas tanto a sus partidarios como a sus contrincantes para lograr el apaciguamiento nacional, ${ }^{23}$ a ojos de la opinión pública el desempeño de Echenique beneficiaba solo a sus correligionarios, siendo marginados o exiliados sus detractores y/o enemigos políticos. Desde diciembre de 1851 se habían exiliado en Chile por cargos de conspiración los generales San Román y Vivanco, sin perder por ello sus respectivos sueldos como militares; y, aunque le ofrecieron sus servicios y consejos, fueron marginados de la vida política tanto Castilla como Elías. En lo referente a las relaciones con los países vecinos, los regímenes de Castilla y Echenique también tuvieron marcadas diferencias. El primero en un gesto de fraternidad internacional fue promotor de un congreso americano celebrado en Lima en 1847, al que acudieron representantes de Bolivia, Chile, Ecuador y Nueva Granada. Mantenía además una estrecha amistad con el general boliviano Belzu, al coincidir ambos por distintas razones en su odio al general José Ballivián depuesto de la presidencia en 1847, siendo afianzada esa alianza con la conversión de Belzu en mandatario de Bolivia a fines de 1848 tras el derrocamiento del general José Miguel de Velasco. Contrariamente a la tranquilidad internacional alcanzada por su antecesor, Echenique entró en un temprano conflicto diplomático con Ecuador por su tácito apoyo a la expedición militar planeada por el general Juan José Flores en contra del gobierno liberal de José María Urbina. A esto se sumó en 1853 el conflicto diplomático con el gobierno boliviano derivado de la circulación de la moneda feble en el sur peruano que condujo a la autorización del congreso a Echenique para declarar la guerra a Bolivia.

22 Ragas Rojas, 2003.

23 Mc Evoy, 1996. 
Para garantizar la lealtad de sus correligionarios y controlar el eventual problema de un conflicto bélico internacional, Echenique brindó un trato especial a aquellos que formaban parte de los altos mandos del ejército: nombró a algunos como ministros (Torrico y Mendiburu), colocó a otros en el congreso (Gutiérrez de la Fuente, Forcelledo, Cisneros, etc.) y, por último, confirió a sus más leales oficiales las principales prefecturas. A esto se añadió el lucro económico de la oficialidad echeniquista. Fernando Casós y Domingo Elías lo denunciaron en sus respectivos folletos y publicaron las listas de los oficiales supuestamente beneficiados con la consolidación de la deuda interna, entre los que destacaban los generales Torrico, Gutiérrez de La Fuente, Deustua, Pezet, Medina, Cisneros, Forcelledo, Vidal, Allende, Suárez, Iturregui, Valle Riestra y Vigil. ${ }^{24}$ La satisfacción de los militares con el gobierno de Echenique se afianzó por las medidas tomadas para resolver el problema de los llamados jefes y oficiales indefinidos, es decir, aquellos que resultaban sin colocación en el Ejército y la Marina por no figurar en el presupuesto nacional. En septiembre de 1853 se dictó una ley por la cual las familias de todos los oficiales excedentes del número fijado en la constitución tenían derecho a montepío, o lo que es lo mismo, a beneficiarse de los descuentos que se hacían a los empleados para socorrer a sus viudas y huérfanos. También se garantizaba el goce de esas pensiones a las familias de los jefes que hubieran muerto bajo la condición de indefinidos con posterioridad a la promulgación de la ley de 1850. Paralelamente, el congreso sancionó una ley en la que se resolvía «que los jefes y oficiales vencedores que después de reformados hayan entrado al servicio, con inclusión de los que hubiesen ascendido a la clase de generales, gocen mientras permanezcan en él, hállense o no colocados, el sueldo íntegro de su clase». ${ }^{25}$ Por último, se amplió el número de las campañas militares que podía contabilizar un oficial para su promoción al incluirse las guerras contra la Confederación Perú-Boliviana en 1838 y 1839 y la invasión de Bolivia de 1841, ordenándose que estas produjeran seis meses de aumento en su tiempo de servicio. Con estas medidas y otras de menor calado que beneficiaban a suboficiales y soldados rasos, Echenique pudo vanagloriarse de que su mejor partido político eran el Ejército y la Marina. Por eso, y convencido de tener absolutamente disciplinadas a las armas nacionales, en sus memorias justificó que en 1854 «con él solo [el ejérci-

24 Casos, 1854, 62; Elías, 1855, 14-15.

25 República Peruana, 1857, 164. 
to], a pesar de tener en contra a la mayoría de los pueblos alucinados, combatí la revolución que se me hizo por más de un año». ${ }^{26}$

Cuando Castilla asumió el liderazgo de la revolución en Arequipa no contaba con ninguna facción de las fuerzas armadas que le apoyara. Tras hacerse con el control de la situación en el sur sin necesidad de un enfrentamiento bélico con las tropas gubernamentales que, más bien, optaron por retirarse de Paucarpata, Castilla emprendió una ofensiva para debilitar y dividir al ejército. Desde el cuartel general cuzqueño de Pampacolca el 28 de marzo decretó que en un plazo de cuarenta días los comandantes de buques de la escuadra y los generales, jefes y oficiales del ejército con los cuerpos que mandaban «se adhirieran al movimiento general de la República, separándose de la obediencia del general Echenique». ${ }^{27}$ Esta disposición vino acompañada de una serie de consideraciones para los militares que la acataran o rechazasen. A los primeros se ofreció conservarles en sus grados y colocaciones respectivas además de reconocerles cómo «beneméritos a la patria en grado eminente», mientras que a los oficiales que se obstinasen en desacatar el llamamiento y continuaran ejerciendo actos de hostilidad contra los movimientos populares se les advirtió que serían separados del ejército y sometidos a juicio como «traidores a la Nación». Por último, Castilla se dirigió a todos los individuos de tropa y les alentó a «abandonar las filas del tirano de la patria» y a incorporarse al ejército libertador con el ofrecimiento de ser gratificados. La medida no surtió efecto con la plana mayor echeniquista que fue la que asumió la conducción de las seis divisiones en que se organizó la fuerza constitucional, a saber, los generales Deustua, Torrico, Pezet, Cisneros, Suárez y Vigil. Sin embargo, el decreto de Castilla iba a tener un progresivo apoyo de parte de una oficialidad insatisfecha con los modales clientelistas del presidente. Un conocido cambio de bando fue el protagonizado por el general Baltazar Caravedo y que refleja la importancia de la reciprocidad en la política. En su condición de prefecto de Lima Caravedo había comandado las tropas gubernamentales que vencieron en Saraja a las milicias revolucionarias de Elías en Ica. Su lealtad hacia Echenique se rompió cuando este desatendió su promesa de perdonar al general Mateo González Mugaburu, un militar que en pleno conflicto bélico se había arrepentido de apoyar a Elías y había obtenido la protección de Caravedo. Pese a las protestas de este, González

26 Citado por Basadre, 1964, II, 956.

27 Oviedo, 1865, XIII, 123. 
Mugaburu fue apresado y objeto de un consejo de guerra. Por ello, Caravedo, a pesar de haber sido premiado por Echenique con un ascenso a general de brigada, renunció a la prefectura limeña y días después se presentó ante los mandos del ejército libertador ofreciéndoles su renuncia a la categoría de general recientemente obtenida. Castilla, en un gesto que daba cuenta de su destreza en manejar el juego de dones y contradones entre los militares, le confirmó el ascenso pese a haber derrotado a la revolución en Saraja porque, según las palabras del propio Caravedo, «comprendió que si la ocasión fue un acontecimiento funesto para la causa nacional, se había hecho justicia a mis servicios anteriores». ${ }^{28}$

Las deserciones en el bando gubernamental y la cooptación de las milicias cívicas movilizadas en el sur por Echenique para la eventual guerra con Bolivia permitieron, en parte, el fortalecimiento del ejército castillista, que también en un primer momento estuvo financiado gracias a la emisión de vales de crédito público que los comerciantes de los departamentos del sur y del norte aceptaron como provisional moneda de cambio. ${ }^{29}$ Sin embargo, la consolidación del poder militar de los revolucionarios en el sur peruano residió en el apoyo del presidente Belzu. Castilla, en un gesto de buena voluntad, ordenó al gobernador de Tacna a que autorizara la devolución a Bolivia de la cascarilla confiscada por Echenique una vez decretado el estado de guerra y como represalia por el internamiento de la moneda feble..$^{30} \mathrm{~A}$ ello siguió la entrega de cincuenta mil pesos al comerciante francés Gabriel Larrieu para que gestionara ante Belzu la compra de armamento y otro tipo de pertrechos. Cuenta el deán Valdivia que el agente francés llegó a La Paz y en un primer momento Belzu displicente sólo le autorizó a comprar armamento a los particulares. Fue en un segundo encuentro en Cochabamba en donde Larrieu convenció al presidente y «Belzu, después de la queja que dio de no haber recibido de Castilla siquiera una carta de insinuación sobre tal asunto [la revolución contra Echenique], dio al francés fusiles, municiones, artillería y la caballada de su tropa». ${ }^{11}$ En concreto, el ejército libertador obtuvo dos mil quinientos fusiles, sesenta y dos mil cartuchos de bala, seis piezas de artillería y quinientos caballos. ${ }^{32}$ Cuando la prensa en Lima denunció esta venta de armas

28 Caravedo, $1855,4$.

29 Basadre, 1964, III, 1074.

30 En 1853 Belzu creó un banco nacional de la quina y con autorización peruana estableció un estanco en Tacna, cuyas reservas alcanzaron la suma de 45.000 pesos. Ver Schelchkov, 2007, 139.

31 Valdivia, 1956, 214.

32 Morales, 1925, I, 475. 
como un acto de traición a la patria, el canciller boliviano Rafael Bustillo no la negó, sino que la justificó en una circular dirigida a las cancillerías americanas el 1 de junio como una forma de proteger los intereses de su país y porque «era ya tiempo de aplicar al gabinete de Lima sus propios principios, de usar de sus mismos ejemplos y de infligir el talión de su propia conducta». ${ }^{33}$

A diferencia del protagonismo del ejército, la participación de la guardia nacional en la guerra civil de 1854 ha sido un asunto apenas tratado por la historiografía. Aunque su existencia se remonta a la época de las reformas borbónicas, desde su constitución en cuerpos cívicos durante el primer año de vida del protectorado del general San Martín, la guardia nacional tuvo un papel fundamental en el inicio y desarrollo de las asonadas políticas de las primeras décadas republicanas. ${ }^{34}$ Las milicias estaban reconocidas constitucionalmente ya que se consideraba que los ciudadanos estaban obligados a contribuir mediante su entrenamiento armado al sostenimiento de la República. Tal fue el principio bajo el cual el presidente Gamarra sancionó el primer reglamento para su organización el 26 de febrero de 1839. La intervención más destacada de las guardias nacionales fue el episodio conocido como la Semana Magna de junio de 1844, fecha en que el pueblo de Lima se organizó en varios batallones de ciudadanos armados al mando del prefecto Domingo Elías para resistir a las tropas vivanquistas comandadas por el coronel José Rufino Echenique. ${ }^{35}$ Aunque el enfrentamiento entre militares y civiles no se produjo finalmente, Elías recibió por la movilización armada de la población el calificativo de «hombre del pueblo» y la posibilidad de postular a la presidencia en 1845 y 1851, siendo derrotado en ambas ocasiones. Elías y Echenique nunca sospecharon que diez años después volverían a enfrentarse en una nueva contienda bélica.

La táctica emprendida a fines de 1853 por Elías para hacer prosperar la revolución fue valerse de las milicias ciudadanas como su soporte militarizado. Aunque su levantamiento en Tumbes apenas tuvo eco en la población y fue rápidamente desactivado por el gobierno, más fortuna iba a tener en su tierra natal Ica en donde el 21 de diciembre de 1853, como autoproclamado jefe político de la República, declaró a los cuerpos de la guardia nacional iqueña «en estado de campaña, con todos los goces y preeminen-

33 Basadre, 1964, III, 1075.

34 Sobrevilla Perea, 2007, 160.

35 Peralta, 1999, 231-252. 
cias que concede la ley a los del ejército». ${ }^{36}$ En el referido decreto convocó a todos los individuos entre quince y cincuenta años a que se pusieran a disposición inmediata del jefe del primer regimiento que ocupaba el convento de San Francisco. En compensación declaró a todos los movilizados exentos «por toda su vida del pago de contribución». Dispuso igualmente que a todo aquel ciudadano que se encontrase sin pertenecer a alguno de los cuerpos cívicos se le destinara irremediablemente al servicio de la Marina. Por último, Elías arengó en su proclama a los soldados de la guardia nacional del siguiente modo:

el ángel protector del destino de los valientes os acompaña con la corona de la inmortalidad. Por mi parte os aseguro, que nacido entre vosotros, me esforzaré en los mayores peligros para patentizaros que, formado por el pueblo, no soy indigno de él.

Este líder del civismo revolucionario en pocos días llegó a conformar una milicia con varios centenares de ciudadanos a los que proporcionó armas que fueron confiscadas a la gendarmería y a particulares. Pero Elías hizo un cálculo erróneo de sus posibilidades políticas y militares y su ejército civil, mal entrenado y peor abastecido, en un lapso de dos semanas fue fácilmente derrotado por la bien pertrechada expedición militar enviada por Echenique.

Una segunda oportunidad se le presentó a Elías al inicio de la guerra civil para hacer de la guardia nacional su arma de disuasión prioritaria. $\mathrm{La}$ coyuntura esta vez había cambiado para este personaje porque acordó con el general Castilla actuar como soporte de su campaña. Así, en marzo de 1854, Elías desde su refugio en Chile aprovechó la retirada del ejército gubernamental de Paucarpata para retornar a Moquegua, una provincia ubicada al sur de Arequipa, y sublevarla con el apoyo de una pequeña milicia que había formado en Arica. Tras lograr su objetivo continuó con la constitución de una división de guardias nacionales conformada por ciudadanos moqueguanos y ariqueños para contener a las tropas comandadas por el general Manuel de la Guarda en el vecino poblado de Tacna. Su plan consistía en que una vez sus milicias hubieran derrotado a las tropas echeniquistas en julio «nos habríamos posesionado de las aduanas de Arica e Islay, sacado de ellas más de cien mil pesos, auxiliado al ejército libertador, y con 600 u 800 hombres habríamos marchado sobre Ica, pudiendo estar por agosto con una fuerte división sobre Lima». ${ }^{37}$ Pero Elías fracasó y lo

36 Registro Oficial, Lima, 27 de diciembre de 1853.

37 Elías, 1855, 21. 
achacó al general San Román, comandante en jefe del ejército libertador del sur, que no permitió el envío de ciento cincuenta hombres de auxilio de la división acantonada en Puno que le había sido solicitada desde mediados de junio. En realidad, el líder civilista pecó de voluntarismo e impericia porque, como había ocurrido en Ica, nuevamente enfrentó a la guardia nacional (mil efectivos mal armados y poco entrenados) con la división de Guarda, reforzada con las tropas comandadas por el general Trinidad Morán (mil quinientos soldados), en la batalla del Alto del Conde el 16 de noviembre de 1854. Tras la derrota, Elías consiguió de nuevo huir y refugiarse en Arequipa.

Según el deán Valdivia, en Arequipa apenas conocido que las tropas del general Morán se acercaban a la ciudad para tomarla, su comandante militar, el coronel Pedro Canseco, decidió retirarse con su guarnición a Chuquibamba. Esta determinación fue cuestionada por el resto de líderes revolucionarios que optaron por destituir a Canseco y entregar a Elías, como emisario reconocido de Castilla, la jefatura política del departamento y el mando de la guarnición. Para enfrentarse por tercera vez al ejército de Morán, al que se sumó sorpresivamente el general Vivanco, Elías apenas contaba con «un escuadrón de cívicos y como doscientos paisanos infantes con diferentes armas y sin municiones a las órdenes del comandante cusqueño Barra, y cuarenta de los cargadores emigrados del puerto de Islay». ${ }^{38}$ La táctica esta vez empleada por el líder civil, secundada por los milicianos arequipeños, no fue la de esperar la embestida del ejército sino que una columna armada atacase por sorpresa al batallón de Vivanco. La acción ocurrida en Pocsi el 25 de noviembre tuvo un inusitado éxito y si bien Vivanco huyó «los vencedores volvieron a la ciudad, conduciendo por trofeos de su rápida victoria oficiales y tropa prisionera, más de 300 fusiles, 12.000 tiros a bala [y] dos piezas de artillería». ${ }^{39}$ Era la primera vez que en la guerra civil los milicianos sorprendían y asestaban un duro golpe al ejército constitucional. Esta hazaña iba a completarse el 1 de diciembre cuando las tropas de Morán y Vivanco iniciaron el asalto de Arequipa. La guarnición militar y los milicianos, conjuntamente, no sólo lograron contenerlo sino que hirieron de gravedad a Vivanco y provocaron con ello que la división atacante se desorganizara y retrocediese sin rumbo. Esta circunstancia provocó la dispersión de la caballería y obligó a Morán a suspender

38 Valdivia, 1964, 218.

39 Llosa, 1855, 14-15. 
el ataque de sus tropas contra una trinchera. Tras catorce horas de combate Morán se rindió y entregó su arma al prefecto. El primer triunfo de Elías sobre el ejército gubernamental se vio empañado por el fusilamiento sin juicio sumario de Morán. En su descargo Elías justificó este acto como un «deber doloroso de justicia» exigido por Arequipa y que «yo no podía contrariarlo, porque a veces el pueblo necesita de estos ejemplos».40

Si con Elías la guardia nacional tuvo un papel fundamental en la contienda del 1854, menos significativo fue su empleo por parte de Castilla y Echenique aunque con una diferencia notable. En el caso de Castilla, el dominio político y militar que alcanzó sobre los departamentos del sur tras la retirada de las fuerzas de Torrico en Paucarpata, inusitadamente le permitió absorber dentro del ejército libertador a los milicianos que estuvieron entrenándose con el propósito de intervenir en la anunciada guerra con Bolivia. Así ocurrió en Puno, Cuzco, Ayacucho, Moquegua y Tacna. Pero en lugar de potenciar una actuación autónoma de los batallones de guardias nacionales, estos fueron incorporados a las distintas divisiones del ejército $\mathrm{y}$, por tanto, quedaron sometidos a la autoridad de la oficialidad castillista. A estos ciudadanos armados Castilla les había ofrecido reconocimientos y premios una vez concluida la empresa revolucionaria. En el caso de Echenique, este consideró que la guardia nacional opacaba al ejército, como prueba el hecho de que durante los tres años de su gestión presidencial no se dictase ninguna normativa específica sobre dicha institución a pesar de estar reconocida en la Constitución de 1839. Su desconfianza hacia las milicias cívicas era tal que a pesar de tenerlas a su favor en la guerra civil, prefirió neutralizarlas o desactivarlas. Por ejemplo, cuando tuvo noticias de que a principios de junio una división de nacionales de la provincia de Piura había derrotado en la hacienda de Macacará a un batallón de sublevados procedentes de Tumbes, los premió, primero, declarando como oficiales del ejército a los jefes de la guardia nacional de Piura y, segundo, concediendo a los individuos de tropa «quedar por toda su vida exceptuados del servicio en el ejército y en la guardia nacional, después de pasadas las actuales circunstancias, a menos que ellos voluntariamente quieran prestarlo». ${ }^{41}$ Es decir, para Echenique el civil en armas debía terminar enrolándose en las filas del ejército por reconocimiento de méritos o por voluntad propia, no tolerándose así la existencia de un cuerpo armado paralelo al ejército y no sujeto al mismo.

40 Elías, 1855, 23.

41 Oviedo, 1865, XIII, 234. 
Cuando el presidente advirtió que el ejército en que tanto había confiado para ganar la guerra acumulaba toda una serie de derrotas, con la consiguiente pérdida del control territorial, promulgó el Decreto del 18 de noviembre de 1854 . Obligaba, en primer lugar, a que se presentaran a los cuerpos del ejército de reserva tanto los desertores del servicio de tropa como los suboficiales y soldados licenciados, premiándose a los primeros con el indulto y a los segundos con un inmediato «enganche de diez pesos». Convocaba, en segundo lugar, voluntariamente a todo particular a enrolarse en el ejército con la promesa de otorgársele diez pesos y además quedar «eximido del pago de contribución o patente por toda su vida». Premiaba, por último, con la libertad inmediata a todo esclavo doméstico o de hacienda que se presentara al servicio del ejército por un tiempo de dos años, «gracia [que] se hará extensiva a su mujer legítima».42 Pero las ofertas de Echenique a los militares que había marginado o perseguido durante su administración, a los ciudadanos que no había alentado a armarse en defensa de la legalidad constitucional como guardias nacionales sino como meros soldados de línea, y, por último, a los esclavos negros a los que tímidamente reconoció unos limitados derechos en el código civil de 1852, no fueron suficientes para obtener el apoyo de estos y revitalizar su fuerza armada.

Castilla hábilmente contraatacó la parte más popular del decreto de Echenique de noviembre con otro elaborado por su asesor liberal Manuel Toribio Ureta y promulgado en Huancayo el 5 de diciembre. En este decreto se proclamó la libertad absoluta de todos los esclavos de la República sin condición alguna y con la promesa de indemnizar a sus expropietarios una vez concluida la guerra. Los ex esclavos se enrolaron en el ejército libertador en un número que se calcula osciló entre dos o tres mil personas, actuando algunos como espías para proporcionar información a los oficiales de Castilla sobre los movimientos del ejército de Echenique. ${ }^{43}$ No fue este el único soporte popular que Castilla supo orientar a su favor. Previamente, había obtenido las simpatías de la mayoritaria población rural hacia la revolución al suprimir el tributo indígena en julio en la ciudad de Ayacucho. Como los indios eran desafectos a la conscripción, colaboraron con el ejército libertador a modo de guerrillas poco formalizadas para hostilizar a las fuerzas echeniquistas en el centro y sur del país en la fase final de la guerra civil.

42 Ibidem, 125.

43 Blanchard, 1992, 197. 


\section{La justicia revolucionaria y el reparto de beneficios}

Tras su triunfo definitivo sobre Echenique en la batalla de La Palma en enero de 1855, Castilla asumió la condición de presidente provisional y procedió a hacer efectivo su compromiso de premiar a los que lo apoyaron. El reparto de dones políticos debía garantizar el logro del objetivo fundamental por el que Castilla había liderado la revolución que era eliminar toda la maquinaría política y militar que sustentaba la «tiranía» de Echenique y abolir la Constitución de 1840 que impedía su reelección presidencial. Para promulgar una nueva carta política y eliminar a los conservadores echeniquistas, conocidos como consolidados y también «mashorqueros», es decir, aquellos que habían medrado tras la candidatura presidencial del general Torrico, Castilla recurrió a los liberales. A unos les confió el poder ejecutivo y a otros les facilitó el control del legislativo. Calificando al suyo como el «gobierno de la moralidad», el «Libertador» entregó a Pedro Gálvez el ministerio de Justicia, Culto y Beneficencia, a Manuel Toribio Ureta el de Gobierno, Relaciones Exteriores e Instrucción, y a Domingo Elías el de Hacienda.

El 5 de febrero de 1855 el gobierno castillista cumplió su promesa de convocar elecciones para una convención nacional que a partir del 15 de junio tuvo la misión de redactar una nueva constitución y, que al mismo tiempo, legitimó al presidente provisorio. El nuevo reglamento electoral permitía el voto de los hombres analfabetos, incluyéndose en este rubro por primera vez a los ex esclavos afrodescendientes, pero introdujo una cláusula inédita que impedía votar a aquellos «diputados, senadores o consejeros de Estado que desde el 20 de marzo de 1851 hasta el 5 de enero de 1855 no sirvieron de manera alguna a los pueblos en la causa de su moralidad y de sus derechos» ${ }^{44}$ La exclusión también afectó a los empleados, militares y agentes de policía que defendieron a la administración echeniquista. Así, un amplio sector de ciudadanos, entre los que también fueron parcialmente excluidos los votantes vivanquistas, quedó inhabilitado de ejercer el sufragio. Con esta polémica decisión electoral se garantizó que la asamblea nacional estuviese dominada por los liberales y que tuviera una amplia base de respaldo popular pero, concomitantemente, que el cumplimiento de sus decisiones quedara a merced de «un Estado dominado por el ejército». ${ }^{45} \mathrm{La}$

44 Basadre, 1964, III, 1097.

45 Peloso, 2001, 21. 
convención nacional concluyó la redacción de la nueva constitución el 13 de octubre de 1856, y esta fue promulgada con serias objeciones por Castilla. El conflicto estuvo en que los liberales fueron consecuentes con su principio doctrinario de limitar el presidencialismo, lo que implicaba otorgar poderes de contrapeso al Legislativo (como fue la intervención del congreso en los ascensos de los militares). La constitución también introdujo la incompatibilidad entre la presidencia provisoria y la candidatura presidencial, por lo que «los días de Castilla en el mando supremo parecían contados. La convención se proponía a sobrevivirle». ${ }^{46} \mathrm{Sin}$ embargo, esta fue disuelta por Castilla el 2 de noviembre de 1857 junto con la convocatoria de un congreso para redactar una nueva constitución, produciéndose a consecuencia de ello la ruptura definitiva de Castilla con los liberales.

De no menor trascendencia que el poder concedido a los liberales fueron las regalías que Castilla otorgó a los miembros de su ejército libertador y a las guardias nacionales que le apoyaron. Los principales beneficiarios fueron los jefes y oficiales que pelearon en la batalla de la Palma. Conocidos popularmente como «los sagrados», el 2 de mayo de 1854 fueron nombrados «beneméritos a la patria en grado heroico y eminente» y se les otorgó una medalla de diez líneas de diámetro en cuya superficie se inscribiría la frase «A los libertadores de su patria». Un decreto complementario se sancionó el 4 de mayo por el que se reconoció el mérito de los jefes y oficiales del ejército y de la guardia nacional que participaron en la defensa de la ciudad entre el 30 de noviembre y 1 de diciembre de 1854 . A estos se les entregó una medalla de oro de diez líneas de diámetro en cuyo centro se debía inscribir «A los valientes de Arequipa». ${ }^{47}$ Finalmente, el 18 de febrero el ministro San Román sancionó la reducción de la fuerza permanente del ejército y la desactivación de las guardias nacionales con «la restitución a sus hogares de aquellos ciudadanos que llenos de abnegación y patriotismo, los abandonaron espontáneamente para consagrarse a la defensa común». ${ }^{48}$ Tras la ruptura con los liberales en 1857 fueron «los sagrados» los que apoyaron de modo incondicional a Castilla en sus últimos años de gobierno y accedieron a colaborar con los políticos conservadores entre los que destacó el sacerdote Bartolomé Herrera.

46 Basadre, 1964, III, 1124.

47 Oviedo, 1865, XIII, 235.

48 Ibidem, 125. 
En lo que respecta a los miembros del Ejército y de la Marina derrotados, Castilla cumplió con su amenaza vertida en plena guerra civil. Por decreto dictatorial del 11 de enero de 1855 ordenó la separación de ambas instituciones «sin grados ni honores, [de] todos los generales, jefes y oficiales que sirvieron activamente a la tiranía de Echenique, y todos los que sin estar en actual servicio permanecieron bajo sus órdenes y no contribuyeron de modo alguno al triunfo de la causa popular». ${ }^{49}$ En la lista de los que cayeron en desgracia destacaron ex presidentes como el mariscal Gutiérrez de la Fuente y los generales Vivanco, Vidal, Torrico y Echenique. El 23 de noviembre de 1855 la convención nacional estableció el juicio de este último, sus ministros y los generales del ejército bajo el cargo de «desorganización de la República y ruina de su hacienda» y en marzo de 1856 resolvió que todos los generales, jefes y oficiales afectados por el decreto de separación presentaran sus hojas de servicio en la inspección general del ejército o la comandancia general de marina para adoptar una resolución definitiva sobre su baja. Finalmente, los convencionales promulgaron la llamada ley de amnistía restringida el 16 de abril de 1856 por el que «quedaron relegados al olvido, las opiniones, actos y delitos políticos de las personas comprometidas en la última administración». ${ }^{50}$ Ello no libró a los llamados militares «consolidados» de ser sometidos a un proceso de investigación por la comisión del crédito público encargada de investigar los actos corruptos de la consolidación de la deuda interna. ${ }^{51}$

La colaboración militar brindada por el régimen belcista al ejército libertador fue retribuida por Castilla con la suspensión sucesiva de la interdicción comercial y el casus belli decretado en tiempos de Echenique. El restablecimiento de las relaciones mercantiles y diplomáticas durante el breve lapso de tiempo que Belzu se mantuvo en el poder se prolongó du rante el régimen de Jorge Córdova, yerno y sucesor político de Belzu. El entendimiento peruano-boliviano se interrumpió tras el golpe de Estado del 9 de septiembre de 1857 en el que José María Linares depuso a Córdova. La tensión se reanudó cuando la dictadura de Linares reasumió los principios políticos del acérrimo enemigo de Castilla, el general Ballivián. De ahí que el gobierno peruano diera refugio a Córdova y apoyara las conspiraciones de los exiliados belcistas en la frontera. ${ }^{52}$

\footnotetext{
49 República Peruana, 1857, 172.

50 Basadre, 1964, III, 1112.

51 Quiroz, 1987.

52 Peralta e Irurozqui, 2000, 128-129.
} 
La exigencia de contraprestaciones a Castilla por parte de las provincias que le apoyaron se puso en marcha apenas se estableció el gobierno provisional. La más significativa fue la creación del departamento de Cajamarca el 11 de febrero de 1855, acto que había ratificado el decreto de la junta departamental del año anterior. El caso de Arequipa también fue significativo. El prefecto Llosa expresó que como recompensa a los sacrificios de esa ciudad estaban «las obras y mejoras que demanda en justa satisfacción de sus necesidades». ${ }^{53}$ Seguidamente pidió la puesta en marcha de las siguientes obras: el colegio de artes, la atención a la agricultura, la protección del comercio del sur, el fomento de la instrucción pública, el restablecimiento del asiento mineral de Caylloma, la reconstrucción de la catedral y la planificación de la cañería interior del agua de Yumina. Sin embargo, la lealtad de Arequipa al régimen no estuvo condicionada por la puesta en marcha de las obras públicas, sino por la orientación ideológica de la convención nacional. Cuando la constitución fue promulgada, inmediatamente estalló una sublevación en el departamento por considerar los conservadores que Castilla los había traicionado al permitir que se atacara los privilegios de la Iglesia. La nueva guerra civil se inició con el pronunciamiento del general Vivanco el 31 de octubre de 1856, que también fue apoyado en Moquegua. Se prolongó hasta el 7 de marzo de 1858 cuando Arequipa fue sangrientamente ocupada por las fuerzas del gobierno. Vivanco huyó y se exilió en Chile, sirviendo este nuevo fracaso para concluir definitivamente el pulso mantenido con Castilla por el poder desde la década de $1840 . \mathrm{La}$ guerra civil de 1856-58 debe considerarse, así, como la continuación y definición del conflicto iniciado en 1854 ya que supuso el fin del regeneracionismo vivanquista, la ruptura definitiva de Castilla con los liberales y su alianza con «los sagrados» y los sectores católicos ultramontanos.

Recibido el 01 de septiembre de 2012 Aceptado el 16 de octubre de 2012

\section{Bibliografía}

Aljovín de Losada, Cristóbal: «Violencia y legitimidad: las revoluciones entre 1827 y 1841», Revista Histórica, Lima, XXXVIII, 1993-1995, 257-274.

Basadre, Jorge: Historia de la República del Perú, Lima, Editorial Peruamérica, 1964.

53 Llosa, 1855, 21.

Anu. estud. am., 70, 1, enero-junio, 2013, 195-219. ISSN: 0210-5810. DOI: 10.3989/aeamer.2013.1.07 
Blanchard, Peter: Slavery and Abolition in Early Republican Peru, Wilmington (Delaware), Scholarly Resources Inc, 1992.

Caravedo, Baltazar: Breve exposición de los motivos que obligaron al general Caravedo a incorporarse en las tropas libertadoras, después de los sucesos de Saraja en que sostuvo al gobierno del S. D. José Rufino Echenique, Lima, 1855.

Casos, Fernando: Para la historia del Perú. Revolución de 1854, Cuzco, Imprenta Republicana, 1854.

Castillo, Fermín del: El general Castillo ante sus conciudadanos desvaneciendo las imputaciones de su acusador o sea la mala fe comprobada de D. Ramón Castilla, Lima, Tipografía de El Heraldo de Lima, 1855.

Chiaramonti, Gabriela: «De marchas y contramarchas: apuntes sobre la institución municipal en el Perú (1812-1861)», Araucaria 9/18, Sevilla, 2007, 150-179.

Elías, Domingo: Manifiesto de D. Domingo Elías a la nación, Arequipa, Imprenta Libre de Mariano Nicolás Madueño, 1855.

Instituto Libertador Ramón Castilla: Archivo Castilla. Manifiestos y Mensajes, Lima, Imprenta del Colegio Militar Leoncio Prado, 1855.

Irurozqui, Marta: «Presentación», Dossier: Violencia política en América Latina, siglo XIX, Revista de Indias, LXIX, 246, Madrid, 2009, 9-16.

Irurozqui, Marta: «Presentación», Dossier: Entre Lima y Buenos Aires. Acción colectiva y procesos de democratización en Argentina, Bolivia y Perú, siglo XIX, Anuario de Estudios Americanos, LXIX, 2, Sevilla, 2012, 415-422.

Llosa, Francisco: Exposición que el prefecto de Arequipa durante la revolución del Perú en 1854 hace a la nación y al gobierno en elogio del patriótico comportamiento de su departamento y en representación de sus necesidades, Arequipa, Imprenta Libre de Mariano Nicolás Madueño, 1855.

Macías, Flavia: «Ciudadanía armada, identidad nacional y Estado provincial. Tucumán 1854-1870», en Sábato, Hilda y Lettieri, Alberto (comps.), La política en la Argentina del siglo XIX. Armas, votos y voces, Buenos Aires, Fondo de Cultura Económica, 2003, 137-151.

Mc Evoy, Carmen: «El legado castillista», Histórica, XX, 2, Lima, 1996, 211-241.

Méndez, Cecilia y Granados Moya, Carla: «Guerra, formación del Estado e imaginario nacional en el Perú», en Albiez, Sarah, et. al., (eds.), Etnicidad, ciudadanía y pertenencia: prácticas, teoría y dimensiones espaciales, Madrid, Iberoamericana-Vervuert, 2011, 93-117.

Morales, José Agustín: Los primeros cien años de la república de Bolivia, La Paz, Empresa Editora Veglia y Edelman, 1925.

Oviedo, Juan: Colección de leyes, decretos y órdenes publicadas en el Perú, Lima, Felipe Bailly Editor, 1865.

Peloso, Vincent: Reformas electorales liberales y el voto popular durante la época del guano en el Perú, Lima, Instituto de Estudios Peruanos, 2001. 
Peralta, Víctor e Irurozqui, Marta: Por la concordia, la fusión y el unitarismo. Estado y caudillismo en Bolivia, 1826-1880, Madrid, CSIC, 2000.

Peralta, Víctor: «El mito del ciudadano armado. La "Semana Magna" y las elecciones de 1844 en Lima», en Sábato, Hilda (coord.), Ciudadanía política y formación de las naciones. Perspectivas históricas de América Latina, México, Fondo de Cultura Económica, 1999, 231-252.

Quiroz, Alfonso W.: La deuda defraudada. Consolidación de 1850 y dominio económico en el Perú, Lima, Instituo Nacional de Cultura, 1987.

Ragas Rojas, José Frank: «Ciudadanía, cultura política y representación en el Perú: La campaña electoral de 1850», tesis para optar el título de Licenciado en Historia, Lima, Pontifica Universidad Católica del Perú, 2003.

República Peruana. Legislación administrativa en el ramo de guerra y marina, desde 1823 a 1857, Lima, Imprenta del Estado por E. Aranda, 1857.

Rubén Vargas Ugarte, Historia General del Perú. La República (1844-1879), Lima, Carlos Milla Batres, 1971.

Sábato, Hilda: «El ciudadano en armas: violencia política en Buenos Aires (18521890)», Entrepasados, XII, 23, Buenos Aires, 2002, 149-169.

Schelchkov, Andrey: La utopía social conservadora en Bolivia: el gobierno de Manuel Isidoro Belzu, 1848-1855, Moscú, Academia de Ciencias, 2007.

Sobrevilla Perea, Natalia: "“Ciudadanos armados": las guardias nacionales en la construcción del Perú de mediados del siglo XIX», en Chust, Manuel y Marchena, Juan (eds.), Las armas de la nación. Independencia y ciudadanía en Hispanoamérica (1750-1850), Madrid-Frankfurt, IberoamericanaVervuert, 2007, 159-183.

Sobrevilla Perea, Natalia: «El proyecto liberal y la Convención de 1855», en Mc Evoy, Carmen (ed.), La experiencia burguesa en el Perú (1840-1940), Madrid-Frankfurt, Iberoamericana- Vervuert, 2004, 223-243.

Valdivia, Juan Gualberto: Las revoluciones de Arequipa, Arequipa, Editorial El Deber, 1956.

Vivanco, Manuel Ignacio de: Exposición que hace el general Vivanco al Perú, y a Arequipa en particular, de los motivos y razones que ha tenido para no tomar parte en la actual guerra civil, Lima, Tipografía de El Heraldo, 1854. 